\title{
A manifestação do ethos nos gêneros retóricos
}

\author{
Joelma Batista dos Santos Ribeiro
}

Mariano Magri

\section{Considerações iniciais}

$\mathrm{E}$ m um processo argumentativo, as dimensões de ethos, logos e pathos aparecem de forma tão imbricada que nem sempre as estratégias utilizadas na argumentação são facilmente detectadas. O logos materializa o discurso por meio dos elementos linguísticos disponíveis e, erroneamente, pode ser entendido como o principal responsável pela persuasão, por ser o mais tangível. Todavia, simultaneamente à materialização do discurso, sempre haverá a revelação de um ethos e o acionamento do pathos. De acordo com Aristóteles (384-322 a.C.), o discurso precisa ser proferido de maneira que o orador seja digno de crédito e que determinados sentimentos sejam despertados para que o auditório concorde com as teses que lhe serão apresentadas. Contudo, embora a relação dessas dimensões argumentativas seja indissociável, o contexto retórico poderá exigir do orador uma acentuação no uso de determinada dimensão argumentativa.

Para se obter a persuasão, haverá contextos em que o uso de argumentos racionais serão mais eficazes do que os psicológicos. Em algumas situações, a credibilidade do orador valerá mais do que quaisquer argumentos racionais, ainda que estejam presentes. Na mesma linha de raciocínio, alguns contextos deverão tocar as paixões do auditório para mobilizá-los na direção 
pretendida. A melhor alternativa nem sempre é fácil de ser encontrada, mas entender o funcionamento de cada uma dessas dimensões ajuda o analista do discurso na interpretação das intenções comunicativas. Este trabalho, entretanto, abordará somente com a dimensão do ethos.

Como o contexto sempre sugere qual dimensão é mais assertiva à persuasão, o objetivo será verificar as estratégicas argumentativas que mais se ressaltam para a manifestação do ethos em cada gênero retórico, ou seja, em cada contexto e finalidade. Para se chegar a esse objetivo, verificamos quais as principais características psicológicas de uma pessoa que podem ser acionadas para formar uma imagem e, por meio de textos clássicos de cada gênero, analisamos a sobressalência dessas características.

\section{Características do ethos}

O conceito de provas retóricas, cunhado por Aristóteles ${ }^{1}$, traz à tona as dimensões que contracenam ao longo de um processo argumentativo. Para esse autor, embora o discurso, representante do lado racional, seja o responsável por materializar os argumentos, a persuasão só é alcançada se outras duas dimensões, representantes do lado psicológico, forem caracterizadas e acessadas de forma efetiva. O discurso, portanto, além de construir sentido aos argumentos, precisa ser proferido de forma que caracterize a imagem do orador como digna de crédito e, além disso, precisa acessar as paixões do auditório com o objetivo de afetá-las e fazer com que os ouvintes experimentem sentimentos que os levem a concordar com os argumentos apresentados.

Na retórica de Aristóteles, o discurso é representado pelo termo logos; a imagem do orador, pelo termo ethos; e as paixões de quem ouve, pelo termo pathos. Para esse filósofo, um processo argumentativo justapõe ethos, logos e pathos e os torna indissociáveis para a obtenção da persuasão. O lado racional, logos, é o responsável por estimular o lado psicológico: ethos e pathos; e a persuasão será alcançada quanto mais efetiva for esta estimulação. Para isso, cada uma dessas dimensões conta com um número extenso de possibilidades de realização. $\mathrm{O}$ logos, por exemplo, coloca à disposição do orador os recursos de ordem lexical, sintática, semântica e estilística que, em cada caso concreto, podem ser usados para mobilizar combinações desses recursos com o objetivo

1 Aristóteles, 2013. 
de criar efeitos linguísticos, tanto em partes isoladas do texto, para acentuar o que se entende como mais relevante, como no texto em sua íntegra, pelo encadeamento das ideias. O pathos, por sua vez, coloca o desafio ao orador para se antecipar no reconhecimento de crenças, costumes, grau de instrução, na medida em que discursar contra os valores de um auditório não se mostra uma forma efetiva de persuadir. O ethos, por fim, e não diferente das outras dimensões, tem o seu universo de estratégias para estimular a imagem do orador de forma efetiva e é sobre essas estratégias que passaremos a falar.

As teorias que versam sobre a construção do ethos ganharam significativas vertentes, em diversas áreas do saber, e apontam para diferentes caminhos, mas este trabalho tomará a teoria de Aristóteles ${ }^{2}$ como referência. De acordo com esse autor, os seres humanos são inclinados a buscar uma verdade, mas "o verdadeiro e o verossímil são apreendidos pela mesma faculdade" ${ }^{3}$ e, por isso, a construção da imagem não é o que se pensa sobre o orador antes de ele discursar, e sim a imagem que é construída ao longo do discurso, verdadeira ou não, pois o princípio é de que não temos acesso ao ser ontológico, e sim àquilo construído pela materialização do discurso. Ainda na linha desse autor, a confiança que o auditório depositará na imagem criada proverá de três causas: a prudência (phrónesis), a virtude (areté) e a benevolência (eúnoia). Abaixo, um quadro resumo das principais características do ethos que podem manifestar confiança em cada uma dessas causas.

Quadro 1 Características do ethos ${ }^{4}$

\begin{tabular}{l|ll}
\hline Phrónesis & Areté & Eúnoia \\
\hline Competência & Confiabilidade & Amabilidade \\
Credibilidade & Determinação & Benevolência \\
Discernimento & Equanimidade & Cortesia \\
Ponderação & Franqueza & Delicadeza \\
Praticidade & Honestidade & Indulgência \\
Prudência & Integridade & Moralidade \\
Racionalidade & Simplicidade & Obsequiosidade \\
Razoabilidade & Sinceridade & Passionalidade \\
Sabedoria & Tolerância & Simpatia \\
Sensatez & Virtude & Solidariedade \\
\hline
\end{tabular}

2 Id., 2013.

3 Ibid., p. 42.

4 Elaborado pelo Grupo ERA, março de 2019. 
De acordo com Eggs $^{5}$, as características elencadas em cada coluna do quadro $\mathrm{I}^{6}$ apontam para uma das provas retóricas. A phrónesis, por contar com características racionais, associa-se fortemente ao logos. Areté, por concentrar características que ressaltam a imagem do orador, associa-se ao ethos. Eúnoia, por coligar-se com o auditório e demonstrar boa intenção, associa-se ao pathos.

A possibilidade de analisarmos essas manifestações, contudo, estão ligadas aos gêneros retóricos. O discurso precisa ser contextualizado em sua finalidade para verificarmos o que ressalta em cada caso. Todavia, para não tornar este trabalho muito extenso, iremos nos limitar a uma das causas da manifestação do ethos: a eúnoia. Os objetivos deste trabalho, então, serão dois: a) verificar se a eúnoia se manifesta de forma mais sobressalente no gênero jurídico, político ou epidítico; e b) explicar, caso sobressaia em alguns dos gêneros, o porquê.

Vale ressaltar, conforme demonstra $\mathrm{Mosca}^{7}$, que dentro de uma mesma argumentação podem ocorrer traços dos três tipos de gêneros. As finalidades aparecem numa relação de dominância e não de exclusão. Passaremos, então, a verificar a relação do ethos com cada gênero retórico.

\section{Ethos e gênero político}

No gênero político, os argumentos levarão em conta que a finalidade do auditório é aconselhar ou desaconselhar um ato futuro. Trata-se de tomar decisões em relação a fazer ou deixar de fazer determinadas coisas. Para verificarmos a potencialidade da manifestação da eúnoia nesse gênero, tomamos um de três clássicos textos do orador grego Demóstenes (384322 a.C.), conhecido como "As três Filípicas", que foram discursos em que Demóstenes conclamou ao povo ateniense a lutar contra o rei Filipe II, da Macedônia, ou seja, aconselha os atenienses sobre o que considera útil fazer.

5 Eggs, 2019.

6 A afirmação de Eggs (2019) não é sobre cada caraterística, mas sim em relação à phrónesis, areté e eúnoia. Nós que relacionamos as características às três causas aristotélicas.

7 Mosca, 1997, p. 32.

8 Como as Filípicas são extensas, adotamos alguns trechos da terceira. 
Embora, atenienses, muitos discursos se pronunciem em quase toda assembleia sobre os ataques injustos que Filipe, desde que concluiu a paz, comente não só contra vós, mas também com todos os demais gregos [...] é preciso falar e agir de maneira que ele ponha termo à violência e seja punido $[\ldots]^{9}$.

Peço, atenienses, que se algo de verdadeiro eu disser com franqueza, nenhum sentimento de cólera contra mim haja por isso de vossa parte ${ }^{10}$.

E o que disso vos resultou, então, foi que, enquanto nas assembleias vos deliciais lisonjeados, ouvindo tudo o que visa prazer, na própria ocorrência dos fatos já estais em extremo perigo ${ }^{11}$.

E é talvez um paradoxo o que vou dizer, mas é verdade: o pior do passado é, para o futuro, o melhor. Mas o que isso significa? É que a situação é má, porque nada, nem pouco nem muito, fazíeis do que era preciso ${ }^{12}$.

Nesses excertos, que remontam as partes iniciais da Filípicas, é possível observar que o autor se colocou como parte da solução de um problema. Incitou a população a modificar a situação em que se encontravam. Embora tenha feito ostensivo apelo ao pathos e poderíamos dizer que a eúnoia se manifestou em todos os trechos, o objetivo não foi utilizar as características que remontam à eúnoia, e sim contrapor atitudes (o orador e auditório), em que a areté do orador se sobressai: determinado, por incitar ao longo dos excertos que é necessário fazer algo contra Filipe; franco, na medida em que sabe que seu discurso não agradaria. Sincero, ao ressaltar o paradoxo e dizer que a situação é ruim por nada ter sido feito.

Entretanto, o que lhe falta para chegar à extrema insolência? Além de destruir cidades, não preside os jogos píticos, o concurso pan-helênico? E, quando ele em pessoa não comparece, não envia seus escravos como agonotetas? Não é senhor das Termópilas e das passagens que levam à Grécia, ocupando esses lugares com guarnições e mercenários? ${ }^{13}$

\footnotetext{
9 Demóstenes, 2001, p. 71-72.

10 Ibid., p. 72-73.

11 Ibid., p. 73.

12 Ibid., p. 74.

13 Ibid., p. 83.
} 
E não somente a seus ultrajes contra a Grécia que ninguém reage, mas nem mesmo aos atos injustos que contra cada um em particular ele comete ${ }^{14}$.

Qual é, pois, a causa do que aí está? Não, não é sem razão e justa causa que os gregos eram, outrora, tão propensos à liberdade e, agora, à escravidão ${ }^{15}$.

Nessa parte, repete-se a extensiva provocação das paixões, mas, da mesma forma, o orador não utiliza eúnoia como meio de manifestação do ethos. Há a construção de um embate por meio de argumentos ad personam ${ }^{16}$. Sobressai, também, o uso da areté, na medida em que o orador, para atacar a pessoa de Filipe, deixa se subentender como detentor de características opostas. Enquanto Filipe é caracterizado como má pessoa, o orador tenta criar a imagem de virtuoso.

Não devemos apensar conhecer esses fatos e daqueles nos defender com ações que sejam bélicas, mas ainda com o raciocínio e o pensamento odiar os que entre nós falam em favor dele ${ }^{17}$.

Por Zeus e por Apolo, eis o que temos que vos afete, quando a reflexão vos fizer ver que mais nada há em vós ${ }^{18}$.

E, se cada um fica inativo, buscando o que quer e procurando ver como não fazer nada, primeiro jamais encontrará os que façam [...] segundo, temo que nos seja forçoso fazer ao mesmo tempo tudo quanto não queremos ${ }^{19}$.

É isso que na verdade eu digo, é isso o que eu proponho. E creio que ainda agora se poderia corrigir a situação se isso fosse feito. Mas se alguém tem alguma proposta melhor que essa, que se pronuncie e aconselhe ${ }^{20}$.

4 Ibid., p. 84.

Ibid., p. 85.

6 Argumentos ad personam consistem na desvalorização do discurso do outro por meio de ataque à sua pessoa ou aos seus atos.

17 Ibid., p. 90.

18 Ibid., p. 93.

19 Ibid., p. 96.

20 Ibid., p. 96. 
Novamente, o apelo às paixões foi ostensivo, mas, também novamente, não pela via da comunhão com o auditório. Os excertos mostraram uma tendência de repetição de comportamento em relação ao discurso. A estratégia desse orador foi acentuar o uso da areté com o objetivo de se colocar como virtuoso, franco, determinado e, ao mesmo tempo, incitar às paixões do auditório para mobilizar para as ações (movere).

No gênero político, portanto, a manifestação do ethos associa-se mais com areté do que eúnoia. Essa afirmação, obviamente, é verdadeira quanto menos mesclado for o gênero e quanto mais a finalidade de aconselhar se sobressair, pois para movimentar o auditório em decidir por uma ação futura, areté precisa se ressaltar, uma vez que ninguém toma uma ação com base em proposta alheia se o proponente não se inspirar digno de crédito.

\section{Ethos e gênero jurídico}

No gênero jurídico, os argumentos levarão em conta que a finalidade do auditório é condenar ou absolver uma causa pretérita. Por se tratar de um julgamento, a intenção do orador será convencer o auditório de que a pessoa julgada é inocente ou culpada, dependendo do lado que se encontre. Para analisar um discurso jurídico e observar o grau de manifestação da eúnoia, tomamos alguns trechos do clássico texto de Cícero (106-43 a.C.), o qual ficou conhecido como "As Catilinárias"21, pois visaram, em sessão plenária no Senado e em praça pública para o povo, culpar o então senador Lúcio Sergio Catilina de uma conspiração para derrubar a república romana.

A seguir, alguns trechos e os nossos apontamentos sobre a sobressalência das características da eúnoia na primeira Catilinária.

E não apenas estes aqui presentes, cuja autoridade tens, pelos vistos, em grande estima, mas a vida em vil apreço; também aqueles cavaleiros romanos, homens da maior honestidade e excelência, e os restantes cidadãos tão valorosos que de pé circundam este Senado, e de quem tiveste ensejo, há momentos, de ver não só a afluência, mas até de reconhecer claramente as disposições e ouvir distintamente os clamores ${ }^{22}$.

21 "As Catilinárias" são compostas por quatro discursos de Cícero. Adotamos a primeira na qual o orador se dirige ao Senado Romano.

22 Cícero, 2006, p. 7. 
A estes tão augustos clamores da República e ao pensamento daqueles homens que sentem desse mesmo modo responderei em poucas palavras ${ }^{23}$.

É que nós, venerandos senadores, vivemos desde há muito envolvidos nestes perigos e nas ciladas de uma conspiração, mas, não sei como, a maturação de todos os crimes e da antiga loucura e audácia veio a rebentar no tempo do nosso consulado. E se, de tamanho bando de salteadores, se suprimir apenas este, poderá parecer talvez que ficamos, por um pequeno espaço de tempo, aliviados da apreensão e do medo; o perigo, porém, há de permanecer e ficará profundamente inculcado nas veias e nas entranhas da República ${ }^{24}$.

A manifestação das características da eúnoia são reveladas nas partes do discurso que Cícero deixa de acusar diretamente Catilina e se dirige aos senadores, seu auditório, com objetivo de conquistar a adesão. O orador mostra-se passional ao revelar o desejo de ser clemente para com os acusados, também ao inculcar o temor no auditório, caso sua recomendação não fosse aceita. Ao colocar-se como porta-voz daqueles que compartilham de sua tese e, ainda, valorizar aqueles que, como ele, são homens valorosos que "circundam o Senado" constrói o ethos de solidariedade e amabilidade que propiciam a comunhão com o auditório.

É meu desejo, venerandos senadores, ser clemente; é meu desejo, no meio de tamanhos perigos da República, não parecer indolente; mas já eu próprio de inação e moleza me acuso ${ }^{25}$.

[...] numa palavra, todas as vezes que me atacaste [Catilina], foi por mim mesmo que te resisti, muito embora eu visse que a minha morte ficaria ligada a uma grande desgraça do Estado ${ }^{26}$.

Nesses excertos há a manifestação da sinceridade (areté) do orador que revela seus pensamentos e sentimentos.

Pois não é verdade que uma personagem tão notável, como era Públio Cipião, pontífice máximo, mandou, como simples particular,

\footnotetext{
23 Ibid., p. 9.

24 Ibid., p. 9 .

25 Ibid., p. 2.

26 Ibid., p. 4.
} 
matar Tibério Graco, que levemente perturbara a constituição do Estado? E Catilina. Que anseia por devastar a ferro e fogo a face da terra, haveremos nós, os cônsules, de o suportar toda a vida? [...]. Havia, havia outrora nesta República, uma tal disciplina moral que os homens de coragem puniam com mais severos castigos um cidadão perigoso do que o mais implacável dos inimigos ${ }^{27}$.

Recorda comigo (Catilina), por fim, aquela noite famigerada de anteontem e logo verás que eu velo com mais ardor pela segurança do Estado que tu pela sua ruína ${ }^{28}$.

Por isso mesmo, parte, como já tantas vezes te disse (Catilina), e, se pretendes, conforme apregoas, atear o ódio público contra mim, teu inimigo, avança já direito ao exílio; [...], refugia-te junto de Mânlio, convoca os cidadãos perversos, separa-te dos homens de bem, move guerra contra a Pátria, exulta com uma sacrílega revolta de bandidos, para que se veja que não foste expulso por mim para o meio de estranhos, mas, sim, convidado a partir para junto dos teus ${ }^{29}$.

Quando te rejeitei (Catilina) do consulado, uma coisa consegui pelo menos: que tu antes pudesses atacar a República como exilado do que maltratá-la como cônsul, e que a tua criminosa empresa mais se pudesse chamar uma arruaça de bandidos que uma guerra civil ${ }^{30}$.

Há, todavia, nesta Ordem de senadores, alguns que, ou não veem aquilo que nos ameaça, ou fingem ignorar aquilo que veem; estes, pela moleza das suas decisões, alimentaram a esperança de Catilina e deram força à conjuração nascente, não acreditando nela; e, por sua influência, muitos; [sic] não apenas os perversos, mas ainda os mal informados, diriam, se eu tivesse punido Catilina, que o tinha feito com crueldade e tirania ${ }^{31}$.

[...] penso que, se for condenado à morte apenas Catilina aqui presente, este flagelo que afecta o Estado pode reprimir-se por um pouco, não suprimir sem [sic] para sempre. Mas, se ele se desterrar a si mesmo e levar os seus partidários consigo, e se recolher, de toda a parte, os demais naufragados da vida e os congregar no mesmo 
lugar, ficará extinta e debelada não apenas esta já tão adiantada doença do Estado, mas até a raiz e o germe de todos os males ${ }^{32}$.

O orador romano mostra-se ponderado, seja ao aconselhar o acusado a deixar a cidade, seja ao dirigir-se ao Senado na tentativa de fazer o acusado culpado. Ressaltam-se as características que manifestam o ethos ligado a racionalidade (phrónesis) como a competência, prudência, ponderação e a sensatez. A credibilidade de Cícero é tecida no discurso à medida que descredita o ethos do acusado, afinal as evidências sobre a conspiração ainda não se encontravam nas mãos do orador. Era necessário persuadir o Senado e, para tanto, Cícero deveria parecer crível.

A phrónesis é a manifestação do ethos que mais se sobressai no discurso de acusação de Cícero que é favorecida pela dimensão lógica das provas. A eúnoia, embora manifeste-se na construção do ethos do orador, não é predominante.

\section{Ethos e gênero laudatório}

No gênero laudatório, os argumentos levarão em conta que a finalidade do auditório é louvar ou censurar pessoas ou ações no presente. Por se tratar de um elogio ou vitupério, o auditório é colocado na posição de espectador. Para analisarmos a manifestação da eúnoia neste gênero, tomamos a apologia do apóstolo Paulo ${ }^{33}$, na qual defende sua autoridade de apóstolo diante da comunidade de Corinto, seu auditório.

Não quero dar impressão de incutir-vos medo por minhas cartas, "pois as cartas, dizem, são severas e enérgicas, mas ele [Paulo], uma vez presente, é homem fraco e sua linguagem é desprezível”34.

Experimento por vós um ciúme semelhante ao de Deus. Desposeivos a esposo único, a Cristo, a quem devo apresentar-vos como virgem pura $^{35}$.

32 Ibid., p. 9.

A apologia paulina que utilizamos se encontra na Segunda Carta aos Coríntios dos capítulos 10 ao 13.

2 Coríntios 10.9 e 10 .

Ibid., 11.2. 
Terá sido falta minha anunciar-vos gratuitamente o evangelho de Deus, humilhando-me a mim mesmo para vos exaltar? Despojei outras Igrejas, delas recebendo salário, a fim de vos servir. E, quando entre vós sofri necessidade, a ninguém fui pesado, pois os irmãos vindos da Macedônia supriram a minha penúria; em tudo evitei ser-vos pesado, e continuarei a evitá- $\mathrm{lo}^{36}$.

E isto sem contar o mais: a minha preocupação cotidiana, a solicitude que tenho por todas as Igrejas! Quem fraqueja, sem que eu também me sinta fraco? Quem tropeça, sem que eu também fique febril? ${ }^{37}$

Eis que estou pronto para ir ter convosco pela terceira vez, e não vos serei pesado; pois não procuro os vossos bens, mas a vós mesmos. Não são os filhos que devem acumular bens para os pais, mas sim os pais para os filhos. Quanto a mim, de bom grado despenderei, e me despenderei todo inteiro, em vosso favor. Será que, dedicando-vos mais amor, serei, por isto, menos amado ${ }^{38}$ ?

Tenho receio de que, quando voltar a ter convosco, o meu Deus me humilhe em relação a vós e eu tenha de prantear muitos daqueles que pecaram anteriormente e não se terão convertido da impureza, da fornicação e da dissolução que cometeram ${ }^{39}$.

Paulo constrói seu ethos por meio da comunhão que estabelece com o auditório ao mostrar-se obsequioso, solidário, benevolente e amável para com os fiéis. A dimensão do pathos é ativada à medida que o orador apresenta os sacrifícios que fez e suas constantes preocupações (passionalidade). A eúnoia permeia toda a apologia, inclusive, coaduna-se aos argumentos lógicos como os de comparação e de sacrifício.

Todavia, julgo não ser inferior, em coisa alguma, a esses "eminentes apóstolos"! Ainda que seja imperito no falar, não o sou no saber. Em tudo e de todos os modos, vo-lo mostramos ${ }^{40}$. 
Conheço um homem em Cristo que, há quatorze anos, foi arrebatado ao terceiro céu - se em seu corpo, não sei: se fora do corpo, não sei; Deus o sabe! E sei que esse homem - se no corpo ou fora do corpo não sei; Deus o sabe! - foi arrebatado até o paraíso e ouviu palavras inefáveis, que não é lícito ao homem repetir. No tocante a esse homem, eu me gloriarei; mas, no tocante a mim, só me gloriarei das minhas fraquezas ${ }^{41}$.

Nesses excertos são ressaltados a competência, a ponderação e sensatez do apóstolo, características éticas da phrónesis. Diferentemente de seus oponentes, Paulo procura não se gloriar da sua autoridade apostólica e de suas experiências espirituais, antes, pondera sobre e admite que se gloriará, porém na fraqueza, pois essa o identifica com o Cristo. A racionalidade com que expressa seu posicionamento revela o discernimento com que realiza as ações.

Não nos gloriamos desmedidamente, apoiados em trabalhos alheios; e temos a esperança de que como progresso da vossa fé, cresceremos mais e mais segundo a nossa regra, levando mesmo o evangelho para além dos limites da vossa região, sem, porém, entrarem campo alheio para nos gloriarmos de trabalhos lá realizados por outros ${ }^{42}$.

Se quisesse gloriar-me, não seria louco, pois só diria a verdade. Mas não o faço, a fim de que ninguém tenha a meu respeito conceito superior àquilo que vê em mim ou me ouve dizer ${ }^{43}$.

A preocupação do apóstolo de revelar-se íntegro, franco e sincero são ressaltados nesses excertos que caracterizam a manifestação da areté. $\mathrm{O}$ principal desafio do apóstolo na apologia é resgatar sua credibilidade que fora questionada pelos seus oponentes, dessa forma, sua estratégia consiste em fazê-la por meio da construção de ethos de confiança.

No gênero laudatório, no nosso caso representado por uma apologia, a manifestação da eúnoia ocorre mais potentemente se comparada às demais manifestações, uma vez que o orador se utiliza da dimensão patética da argumentação para levar o auditório a louvar ou censurar.

$41 \quad$ Ibid., 12.2-5.

42 Ibid., 10.15 e 16.

43 Ibid., 12.6. 


\section{Considerações finais}

O objetivo deste trabalho foi analisar as estratégicas argumentativas que mais se ressaltam para a manifestação do ethos em cada gênero retórico. Para tanto, verificamos quais as principais características de um orador são possíveis para a criação de uma imagem e, auxiliados pelo quadro classificatório elaborado pelo Grupo ERA e, ainda pesquisas bibliográficas, relacionamos essas características com as três causas aristotélicas para a manifestação do ethos, quais sejam, a prudência (phrónesis), a virtude (areté) e a benevolência (eúnoia).

Uma vez mapeadas, fizemos um cruzamento das causas com os gêneros retóricos. Embora seja difícil encontrar um gênero puro, optamos por textos clássicos, os quais tenderam a ressaltar as finalidades de gênero retórico. A partir da análise de trechos dos textos, concluímos que a manifestação do ethos se deu conforme abaixo:

- Para o gênero político, a areté foi o que mais se destacou. Como a finalidade do político é aconselhar ou desaconselhar, o orador acentuou as próprias características pessoais para tornar-se digno de crédito.

- Para o gênero jurídico, a phrónesis apareceu com maior incidência. Como a finalidade é destruir o argumento do opositor, o uso de provais racionais foi preponderante para manifestação de um ethos.

- Para o gênero laudatório, a eúnoia foi a que mais se sobressaiu. Como a finalidade é elogiar ou censurar, o orador acentuou o acesso às paixões para se conferir merecedor de crédito.

É importante ressaltar que os resultados levaram em consideração uma relação de preponderância. $\mathrm{O}$ uso de provas racionais e psicológicas é entrelaçado e quase sempre será possível encontrar areté, prhónesis e eúnoia em algum grau dentro de um processo argumentativo. 


\section{Referências}

ARISTÓTELES. Retórica. São Paulo: Edipro. 2013.

BÍBLIA DE JERUSALÉM. 4. ed. São Paulo: Paulus, 2006.

CÍCERO, M. T. As Catilinárias. Tradução de Maximiano Augusto Gonçalves. São Paulo: Martin Claret, 2006.

DEMÓSTENES. As três Filípicas: oração sobre as questões da Queroneso. São Paulo: Martins Fontes, 2001.

EGGS, E. Ethos Aristotélico, Convicção e Pragmática Moderna. In: Amossy, R. (Org.) Imagens de si no Discurso: a Construção do Ethos. São

Paulo: Contexto: 29-56.

MOSCA, L. do L. S. Retóricas de ontem e de hoje. São Paulo: Humanitas, 1997.

ZAMA, C. Os três grandes oradores da antiguidade. Bahia: Wilcke Picard, 1896. 